\title{
Global warming comes to tobacco control
}

\section{Kenneth E Warner}

In the annals of this journal, few articles have struck me quite as unusual in their subject matter as the contribution by Smith et $a l^{1}$ in this issue. The idea that tobacco contributes to global warming is not new. Geist ${ }^{2}$ long ago alerted us to the costs of deforestation caused by the growth and flue-curing of tobacco, and of course smokers release enormous amounts of noxious gases into the atmosphere as they puff on their six trillion cigarettes each year. But that tobacco control contributes to global warming... well that is a novel thought, and a disquieting one at that. For the first time in the history of tobacco control (at least the first time of which I am aware), Smith and her colleagues confront us with the (obvious-once-you-thinkabout-it) fact that our own activitiesour efforts to prevent children from beginning to smoke, our service provision to smokers wanting to quit and our implementation of policies to protect non-smokers from secondhand smokeare all implicated in the manmade disaster of climate change. To quote the immortal Pogo, we have met the enemy and he is us.

To be fair, Smith and her colleagues are not in the least bit accusatory or even (intentionally) provocative. Indeed, in a most disarming manner-a matter-of-fact calculation of the carbon costs of four types of smoking cessation services (text message support, telephone counselling, group counselling and individual counselling) - the authors unintentionally slap us in our face as the recognition dawns that their modest ambition has far greater implications for our field, and indeed for all fields of public health endeavour. The authors' stated bottom line is that 'Smoking cessation services have small carbon footprints and [are] cost-effective after accounting for the societal costs of greenhouse gas emissions.' But the unstated bottom lineperhaps the more important one-is that

Correspondence to Professor Kenneth E Warner, Department of Health Management and Policy, School of Public Health, University of Michigan, 1415 Washington Heights, Ann Arbor, Ml 48109-2029, USA; kwarner@umich.edu tobacco control and virtually all other public health endeavours must join the 21 st century in recognising, and addressing, the fact that we too contribute to climate change through everything we do.

The study per se is quite straightforward. The authors use standard measures from the field of carbon footprint estimation. Travel, for patients and staff going to and from cessation clinics, generates $0.25 \mathrm{~kg}$ of carbon dioxide equivalents $\left(\mathrm{CO}_{2} \mathrm{e}\right)$ per kilometre, while primary care clinic spaces contribute $65.79 \mathrm{~kg}$ of $\mathrm{CO}_{2} \mathrm{e}$ emissions per square metre per year. Air-conditioned office space is far more greedy consuming $154.30 \mathrm{~kg}$ per $\mathrm{m}^{2}$ per year. Emissions attributable to office equipment (computers and the like) add more. Using the phone dials is at $0.0075 \mathrm{~kg} \mathrm{CO} 2 \mathrm{e}$ per minute. And texting, for text message support of cessation, emits at the rate of $4.17 \times 10^{-6} \mathrm{~kg} \mathrm{CO}_{2} \mathrm{e}$ per message. (Parents take note: This means that the average teenager's texting, at the (older generation) inconceivable rate of 100 text messages per day, is responsible for adding $0.15 \mathrm{~kg}$ of carbon equivalents to the atmosphere annually. That is more than the weight of an iPhone itself!)

The authors determine the number of units of each category involved in producing each specific smoking cessation service and multiply them by these $\mathrm{CO}_{2} \mathrm{e}$ estimates. They then multiply these results by the UK Department of Energy and Climate Change's estimate that carbon emissions cost $£ 0.028$ per $\mathrm{kg}$ of $\mathrm{CO}_{2} \mathrm{e}$, and, voila, they have estimated the carbon costs associated with the four smoking cessation services of interest. Combined with data on the other costs of these services and their output in terms of quality-adjusted life years gained for lifetime quitters, the calculations permit the authors to assess the costeffectiveness of smoking cessation services including their contribution to carbon emissions.

The good news is that carbon emissions per smoking cessation patient (8.1$16.3 \mathrm{~kg} \mathrm{CO}_{2} \mathrm{e}$ ) are far lower than the National Health Service (NHS) estimate of average emissions per outpatient visit
(50 kg CO $\mathrm{CO}_{2} \mathrm{e}$. As such, smoking cessation services-well documented previously to be highly cost-effective healthcare interventions ${ }^{3}$-remain so after inclusion of carbon costs.

Some readers may be tempted to dismiss this analysis as of little interest and consequence. That would be a mistake. In England, we learn, the NHS emissions of carbon equivalents account for a quarter of all public sector emissions, and $3 \%$ of emissions from all sources in the UK. Carbon emissions create genuine social costs. Therefore, their inclusion in calculating the costs of health services is appropriate. Increasingly it may become necessary. The UK government has developed legally binding emissions targets. In 2009 , in accordance with the government's policy, the NHS pledged to reduce its emissions by at least $10 \%$ by 2015 . The NHS seeks to prioritise health services that are both clinically effective and produce low emissions. Analyses such as the one in this issue will be essential to evaluate services in light of the dual interest in better health for both patients and our climate.

But are analyses such as that by Smith et al good enough? Much as I admire the authors' aspirations, what is excluded from this study raises many questions about the completeness of the carbon cost calculations. As the authors readily admit, they failed to consider such sources of emissions as recruitment costs, water use and clinical waste, which they say 'are likely to generate a large amount of emissions.' They left consideration of the carbon costs associated with cessation medications to another study.

More troublesome-and this is an issue for all of cost-effectiveness analysis, not simply the incorporation of carbon costs - the authors ignore costs and benefits (in this case emission costs and benefits) that are directly altered by virtue of the success of the cessation interventions. Consider first, as noted at the outset, that smokers emit noxious gases into the atmosphere when they smoke. Helping them to quit smoking reduces these emissions by virtue of reducing the burning of tobacco. That is a clear benefit when measuring net emissions. Second, the cessation-reduced demand for cigarettes reduces the demand for flue-cured tobacco, and hence diminishes the destruction of forests-another benefit. Third, reduced demand translates into reduced manufacture of cigarettes, again diminishing production-related greenhouse gas emissions. Fourth, helping smokers to quit reduces the need for later 
smoking-related healthcare surgical procedures and medical care. Those interventions themselves create carbon dioxide equivalents and, arguably, should be treated as yet another benefit-a $\mathrm{CO}_{2} \mathrm{e}$ reduction-of successful smoking cessation. On the other side of the ledger, and a fifth large category of omissions from the study, because people who quit smoking live longer, they contribute to greenhouse gases in ways both medical-their later treatment for old-age diseases - and nonmedical - the basics of living.

To their credit, the authors acknowledge most of these additional costs and benefits, but their omission from the study raises questions about the accuracy of their assessment of the $\mathrm{CO}_{2} \mathrm{e}$ implications of smoking cessation interventions. Logically, it seems highly likely that the consequences of these omitted emissions would be larger than those measured in the study, probably dramatically so. And ultimately, the societal interest is in the net effects of activities on greenhouse gas emissions. The problem of this gaping hole in the analysis is compounded by giving casual readers a false sense of precision by using data estimates with multiple significant digits. Recall, for example, the 4-digit precision of the estimate of annual carbon emission equivalents for primary care clinic space $\left(65.79 \mathrm{~kg} \mathrm{CO}_{2}\right.$ e per $\mathrm{m}^{2}$ ).

Where does this leave us? I conclude that the specifics of the study leave the analysis incomplete, likely very much so, for the reasons given (ie, the omissions, not the included calculations). But this paper deserves a place in the journal because its larger message is entirely novel, timely and very important. It is easy and natural for those of us in tobacco control to focus laser-like on our successes and failures in reducing the illness and death toll of smoking. It is perhaps less natural for us to seriously contemplate the other social implications of what we do. This paper forces us to do that. Our world is already suffering the consequences of climate change, and the future implications are dire. As citizens of the globe, we have a responsibility to pay attention to our carbon footprint and to do what we can to diminish it. Smith and her colleagues mention, for example, that we can consider the frequency and location of cessation counselling services in contemplating ways to reduce the travel associated with counselling. One hopes that this paper will leave a permanent footprint on the entire field of tobacco control, encouraging us to be sensitive to our professional contribution to greenhouse gases as well as to how we lead our personal lives.

Competing interests None.

Provenance and peer review Commissioned; internally peer reviewed.

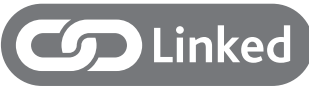

- http://dx.doi.org/10.1136/tobaccocontrol-2012050672

Tobacco Control 2013;22:289-290.

doi:10.1136/tobaccocontrol-2013-051129

\section{REFERENCES}

1. Smith AJ, Tennison I, Roberts I, et al. The carbon footprint for behavioural support services for smoking cessation. Tob Control 2013;22:302-7.

2. Geist HJ. Global assessment of deforestation related to tobacco farming. Tob Control 1999;8:18-28.

3. Ruger JP, Lazar CM. Economic evaluation of pharmaco- and behavioral therapies for smoking cessation: a critical and systematic review of empirical research. Ann Rev of Public Health 2012;33:279-305. 